International Journal of Forensic Science \& Pathology (IJFP)

ISSN 2332-287X

\title{
Fatal Intoxications with Para-Phenylenediamine in Upper Egypt
}

Mohamed $\mathrm{KM}^{1 *}$, Hilal MA², Nady S. Aly ${ }^{1}$

Research Article

${ }^{1}$ Assiut Chemical Laboratory, Medico-Legal Department, Ministry of Justice. EGYPT.

${ }^{2}$ Forensic Medicine and Clinical Toxicology Department, Faculty of Medicine, Sohag University, EGYPT.

\begin{abstract}
Para-phenylenediamine (PPD) is used alone or in combination with Henna as hair dye or skin decoration. A five year retrospective study from 2007 to December 2012 was conducted at Assiut Forensic Chemistry Laboratory of Medic-legal Department, Assiut, to understand the magnitude and pattern of accidental, suicidal and homicide poisoning by PPD among males and females in Upper Egypt. During this period, a total of 84 poisoning cases are reported. The suicidal, homicidal and accidental cases were $(91.7 \%),(7.1 \%)$ and $(1.2 \%)$, respectively. The suicidal poisoning of females was higher $(67.9 \%)$ than of males $(32.1 \%)$. Most of the PPD deaths were between the third and fourth decades of life. PPD is detected by HPLC-DAD in stomach contents, blood, liver and urine samples. The cases are reported with the advice "public education and strict control over the sale and distribution of PPD should be done to reduce poisoning by this agent.
\end{abstract}

KeyWords: Paraphenylenediamine; Acute poisoning; Detection; HPLC-DAD.

\section{*Corresponding Author:}

Khaled M. Mohamed,

Assiut Chemical Laboratory, Medico-Legal Department, Ministry of Justice. EGYPT.

Tel: +20882324038; Fax: +20882324038

E-mail: khaled.masoud@yahoo.com

Received: February 23, 2014

Accepted: April 12, 2014

Published: April 17, 2014

Citation: Mohamed KM, Hilal MA, Nady S. Aly (2014) Fatal Intoxications with Para-Phenylenediamine in Upper Egypt. Int J Forensic Sci Pathol. 2(3), 19-23. doi: http://dx.doi.org/10.19070/2332-287X-140007

Copyright: Mohamed $\mathbf{K M}^{\odot}$ 2014. This is an open-access article distributed under the terms of the Creative Commons Attribution License, which permits unrestricted use, distribution and reproduction in any medium, provided the original author and source are credited.

\section{Introduction}

Para-phenylenediamine (PPD) is an azo dye intermediate used for dying furs, photochemical measurements, as a photographic developing agent, as an intermediate in manufacture of antioxidants and as accelerators for rubbers. In some African and Asian countries, this chemical is used alone or in combination with Henna for dyeing of hair and skin [1-3]. Unfortunately, a vast numbers of suicidal, homicidal and accidental poisoning cases involving PPD were recorded [4-6].

Poisoning symptoms after oral intake include vomiting, epigastralgia, edema of the face, neck and pharynx, dyspnea, acute renal failure, rhabdomyolysis, hemolysis, methemoglobinemia, hepatic disorders and others can occur [7, 8]. In 20 fatal p-phenylenediamine poisoning cases, convulsion, facial edema and cyanosis were characteristic, and edemas of the epiglottis and vocal folds were observed in all cases [9].

PPD is rapidly absorbed into blood through mucous membranes of the digestive tract after its oral intake, and metabolized into quinonediimine, which acts as a cytotoxin. It is acetylated into $\mathrm{N}$ acetyl-PPD and N,N-diacetyl-PPD as the major metabolites for detoxification to be excreted into urine [10-12].

PPD has been detected in blood, urine and gastric content by gas chromatography-mass spectrometry (GC-MS) after liquid-liquid extraction $[13,14]$. Methods involving liquid chromatography (LC) with electrochemical detector [15], ultraviolet [15], diode array [16], or MS detection [17] for quantification of PPD and its metabolites in urine and keratinocyte cell were also reported.

The aim of this study was to determine the number of PPDrelated deaths in Upper Egypt between the years 2007-2012 detail the demography and toxicology findings, and also compare PPD death rates for those years. In addition, a method for extraction and screening of PPD in biological samples by HPLC-DAD was developed.

\section{Methods and Materials}

\section{Chemicals}

All solvents were chemical grade from Sigma. PPD and aniline (internal standard, IS) (>98\%) were purchased from Merck. Dichloromethane (98\%), acetonitrile (99.9\%), ammonium hydroxide (33\%) and potassium dihydrogen phosphate (98-100.5\%) were purchased from Sigma-aldrich (Germany). Blank human blood was obtained from Blood Transfusion Service (Sohag University Hospital). Ethical approval from the local ethical review committee was obtained for the use of this blood.

\section{Detection of PPD by HPLC-DAD}

For urine samples, $0.5 \mathrm{ml}$ are hydrolysed in $0.5 \mathrm{ml}, 12 \mathrm{~N} \mathrm{HCl}$ for $1 \mathrm{~h}$ at $100{ }^{\circ} \mathrm{C}$ and alkalized with conc. ammonium hydroxide. For liver, $1.0 \mathrm{grm}$ is homogenized in $5 \mathrm{~mL}$ water.

To $0.25 \mathrm{~mL}$ hydrolysed urine, $1.0 \mathrm{~mL}$ blood or $1.0 \mathrm{~mL}$ homog- 
enized liver were added $100 \mu \mathrm{L}$ of $100 \mu \mathrm{g} / \mathrm{mL}$ aniline (IS), 0.25 $\mathrm{mL}$ of conc. ammonium hydroxide $(33 \%)$ and $6.0 \mathrm{~mL}$ of dichloromethane. The tubes were then mixed at the rate of $40 \mathrm{rpm}$ for 20-minutes and centrifuged at $3200 \mathrm{rpm}$ for 5-minutes. The organic layer was transferred to a second $10-\mathrm{mL}$ polypropylene tube containing $0.5 \mathrm{~mL}$ of $1.0 \mathrm{M}$ hydrochloric acid. The tubes were then vortex mixed for 5-minutes and centrifuged at 3200 rpm for 5-minutes. The organic layer was discarded. To the remaining aqueous solution, $150 \mu \mathrm{L}$ of conc. ammonium hydroxide and $2.0 \mathrm{~mL}$ of dichloromethane were added. The tubes were then centrifuged at $3200 \mathrm{rpm}$ for 5-minutes. The organic layer was transferred to $5-\mathrm{mL}$ glass tubes and evaporated to dryness. The dried extracts were reconstituted in mobile phase, vortex mixed for 30 -seconds and $100 \mu \mathrm{L}$ was injected into the HPLC system.

The HPLC instrument (Agilent; USA) consisted of an Agilent technologies 1200 series quaternary pump combined with an Agilent 1200 series photo diode array detector (USA), an Agilent 1200 series vacuum degasser (USA) and an Agilent autosampler injector. Chromatographic separation was performed on a Zorbax eclips-C18 $(150 \mathrm{~mm} \times 4.6 \mathrm{~mm}, 5 \mu \mathrm{m})$ column (USA) maintained at $25^{\circ} \mathrm{C}$. The mobile phase consisted of acetonitrile:buffer $(0.01 \mathrm{M})$ potassium dihydrogenphosphate $(20: 80, \mathrm{v} / \mathrm{v})$, adjusted to pH 5.0 with $0.1 \mathrm{M}$ sodium hydroxide and a flow rate of $1.0 \mathrm{~mL} /$ min. The detector was set to scan from 200 to $800 \mathrm{~nm}$ and had a discrete channel set at $240 \mathrm{~nm}$.

\section{Cases}

Eighty-four cases of fatal acute PPD poisoning were admitted to Upper Egypt hospitals (Assiut, Sohag, Luxor, Qena, Aswan) for evaluation and management within the period 2007-2012. Full autopsies were investigated by the Office of the Chief Medical Examiner, Medico-legal department, Ministry of justice. Blood, urine, gastric contents, liver and kidney samples were taken for routine clinical and forensic toxicological testing. The history, clinical manifestations and management were obtained from the clinical sheets of the cases from the receiving hospitals.

\section{Results and Discussion}

\section{Case studies}

In the present study 84 decedents intoxicated by PPD and admitted to some Upper Egypt hospitals have been recorded. The data including: sex, age, residence, manner of toxicity, time and cause of death, were studied statistically.

The highest number of toxic cases $(31 \%)$ was recorded in year 2010 as illustrated in Figure 1. This may be referred to the events of the revolution of Jan. 252011 which is diverting the attention of Egyptians. Concerning the number of PPD toxic cases in relation to governorate it has been found that the highest numbers were in Qena, Luxor and Sohag cities, respectively while less numbers were found in Aswan and Assiut cities as shown in Figure 2. This can be explained by the fact that the use of PPD as a hair dye and as a cosmetic differs in popularity in different residences where it is highly used in South Valley governorates.

The relationship between the gender and the number of toxic cases in different governorates is shown in Figure 3, where the number of females was higher than that of males $(67.9 \%)$ and $(32.1 \%)$ respectively. This referred to the close relationship between females and cosmetics in general and the cheapness of this stone making it in the reach of their hands. Figure 4 shows the relationship between residence and number of toxic cases. The number of toxic cases was significantly higher in rural areas than urban areas. This was due to the more use of the black rock for cosmoses in rural areas.

Concerning the manner of death, the suicidal cases were the highest $(91.7 \%)$ followed by homicidal $(7.1 \%)$ and lastly accidental $(1.2 \%)$ as shown in Figure 5. The causes of committing that crime were mainly due to psychological problems, financial causes and illegal pregnancy respectively as illustrated in Figure 6.

The most common cause of death was renal failure $(67.9 \%)$ followed by asphyxia $(22.6 \%)$, ventricular fibrillation $(9.5 \%)$ then circulatory failure $(6 \%$.), as presented in Figure 7 . Renal failure had been developed most probably due to dehydration, shock and rhabdomyolysis and the direct nephrotoxicity of PPD.

\section{Toxicological analysis}

The presented extraction procedure offers a rapid way to isolate PPD from the biological samples whereas extraction with dichlo-

Figure 1: Hair dye deaths by years in Upper Egypt in the period 2007-2012

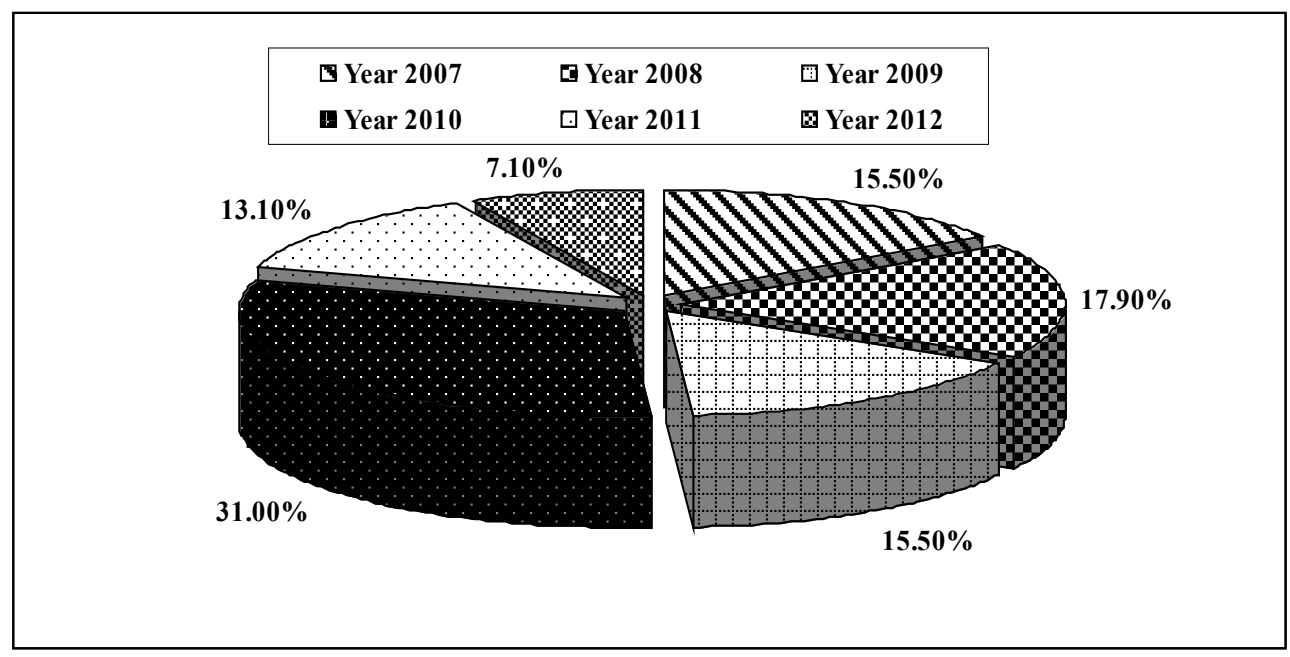


Figure 2: Years distribution of PPD deaths in relation to governorates

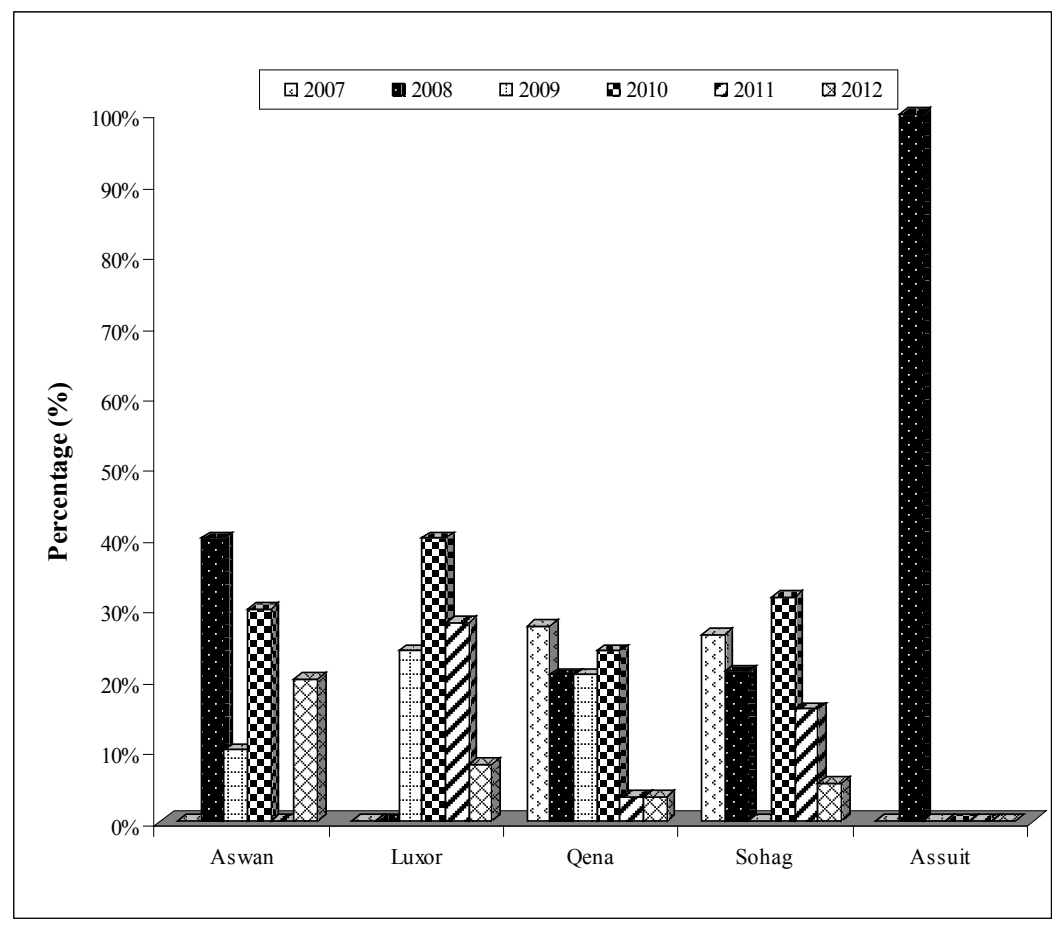

Figure 3: Gender distributions of the PPD deaths in relation to governorates

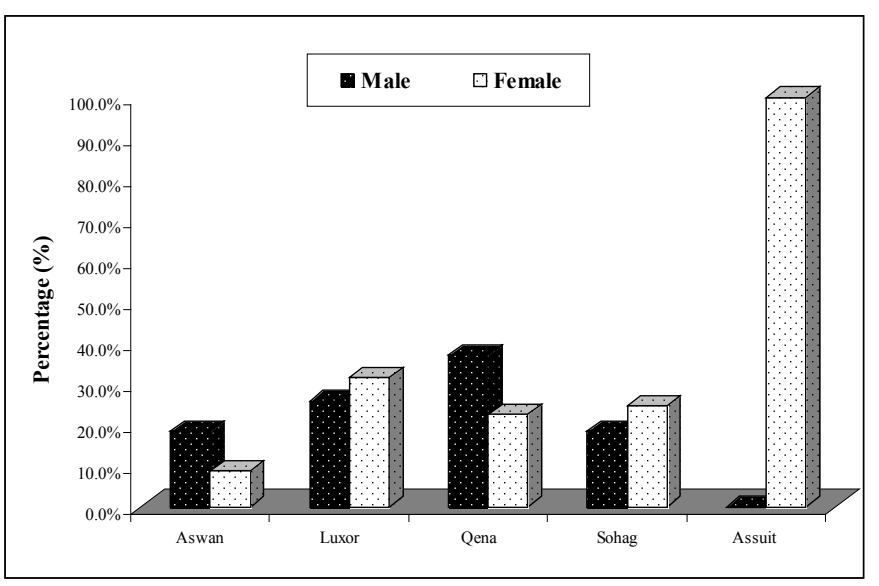

Figure 5: Manner of PPD in Upper Egypt in the period 2007-2012

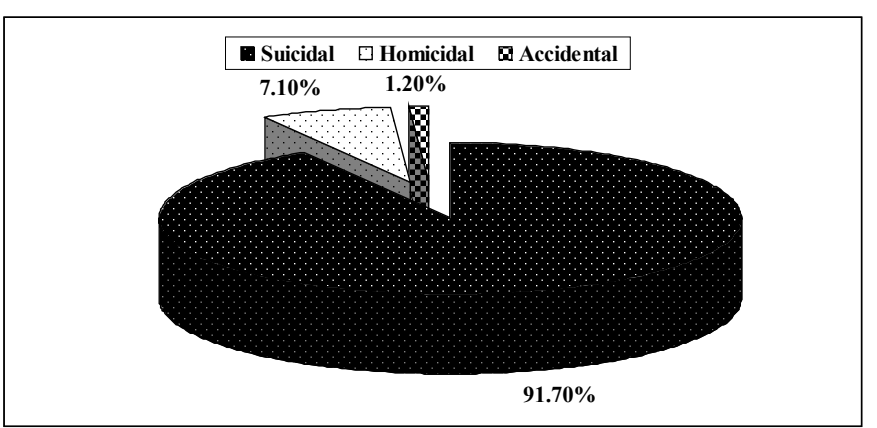

Figure 4: Distribution of the PPD deaths in relation to gender \& residence

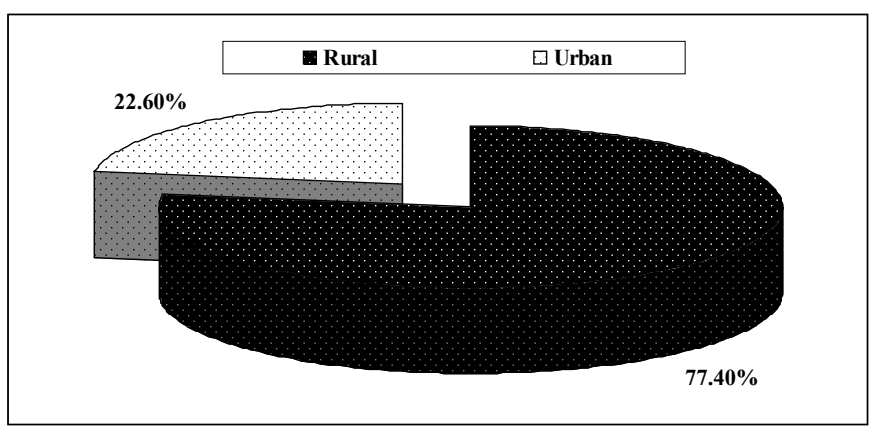

Figure 6: Motive of PPD deaths in Upper Egypt in the period 2007-2012

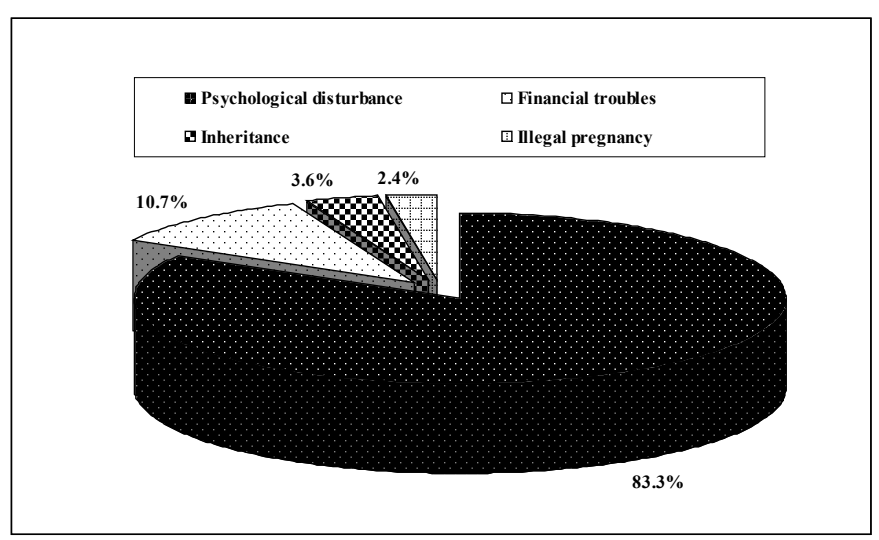


Figure 7: Cause of death after ingestion of PPD

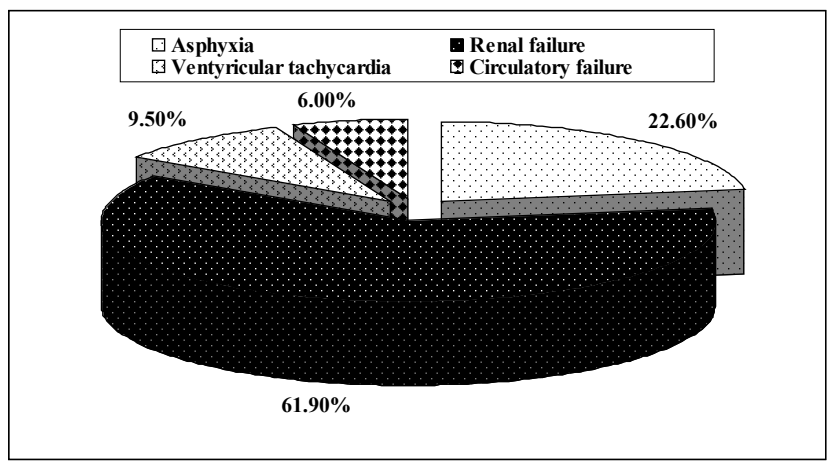

Figure 8: HPLC chromatograms after analysis of a) blank urine, b) spiked urine sample with PPD and C) urine sample collected for toxic case by PPD.
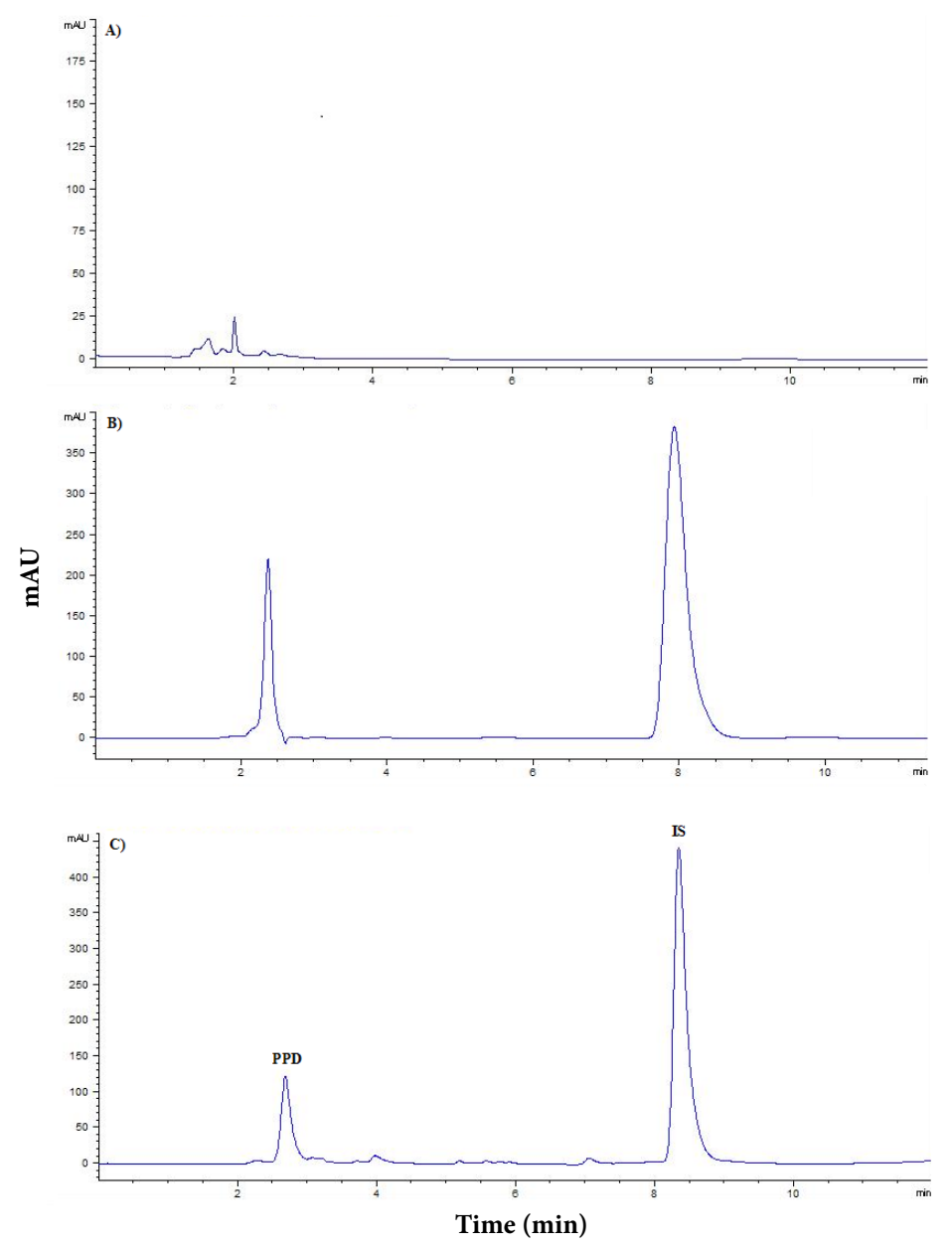

romethane in the presence of ammonia and subsequent purification by back-extraction into hydrochloric acid results a clean HPLC chromatograms and excellent peak shape for PPD and internal standard. The limit of detection of PPD was $0.25 \mu \mathrm{g} / \mathrm{mL}$ based on signal-to-noise ratio $\geq 3$ (determined by peak height). Figures 8 and 9 show HPLC chromatograms for the analysis of a) blank blood and urine samples b) spiked samples with PPD and c) human urine and blood samples collected from autopsy cases related to PPD. The peaks for PPD and IS were also investigated by photo-diode array detector and found to be pure (peak purity more than 999).

Urine samples was digested with hydrochloric acid prior of extraction due to the main metabolite $\mathrm{N}, \mathrm{N}$-diacetyl-PPD presents in high concentration level in urine sample [15].
Quantification of PPD in blood and urine samples was checked by the present method. Critical degradation was found during and after extraction, moreover PPD was unstable in biological samples, this due to the auto-oxidation of PPD by air and light [1819]. Therefor this method is only used for screening of PPD in biological samples.

\section{Conclusion}

In conclusion, further studies must be done to fined effective antidotes against that aggressive rapidly killing poison. A programme of public education and restriction of PPD is urgently required in Qena and other affected nations. An educational programe di- 
Figure 9: HPLC chromatograms after analysis of a) blank blood, b) spiked blood sample with PPD and C) postmortem blood sample collected from autopsy case.
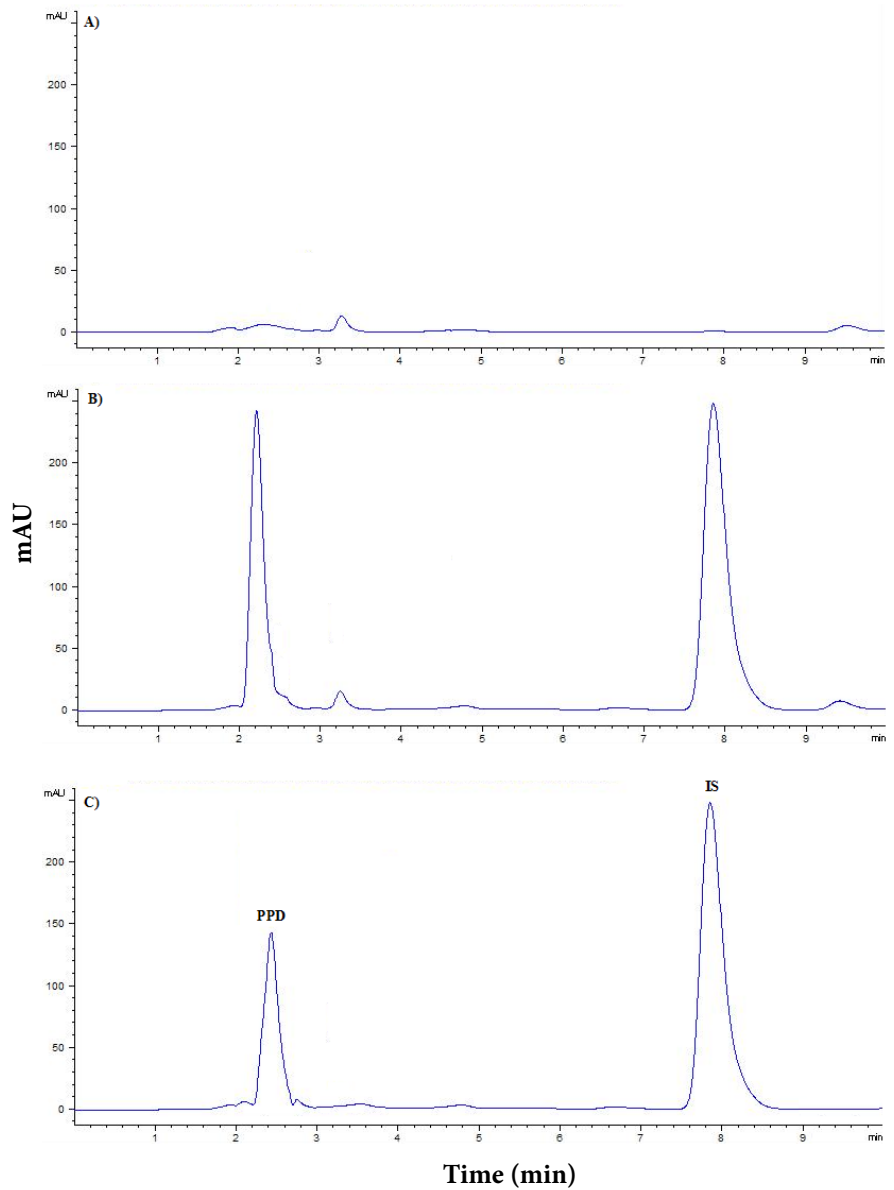

rected to the physicians in the affected areas to increase awareness of the urgency of early hemodialysis for saving the toxic cases.

\section{Acknowledgments}

The authors greatly acknowledge colleagues and employees of the Assiut Chemical Laboratory, Medico-Legal Department, Ministry of Justice, for their assistance and roles to accomplish this work.

\section{References}

[1]. Ashraf W, Dawling S, Farrow LJ. Systemic paraphenylenediamine poisoning: A case report and review. Hum Exp Toxicol.1994;13:167-170.

[2]. Chugh KS, Malik GH, Singhal PC. Acute renal failure following paraphenylenediamine (hair dye) poisoning: report of two cases. J. Med 1982;13:131-137.

[3]. Zeggwagh AA, Aboukal R, Madani R, Zerkaoui A, Hamafi , Kerkeb O. Thrombus ventriculaire gauche et, myocardite toxique induite par la paraphénylène diamine. Ann Fr Anesth Reanim 2003:19:639-641.

[4]. Kumar S. Suicide by para-phenylenediamine Poisoning. J Indian Acad Forensic Med 2010:32:163-164.

[5]. Shalaby SA, Elmasry MK, Abd-Elrahman AE, Abd-Elkarim MA, AbdElhaleem ZA. Clinical profile of acute paraphenylenediamine intoxication in Egypt. Toxicol Ind Health 2010;26:81-87.

[6]. Chrispal A, Begum A, Ramya I, Zachariah, A Hair dye poisoning-an emerging problem in the tropics: an experience from a tertiary care hospital in South India. Trop Doct 2010:40:100-103.

[7]. Takahashi N, Ishizawa J, Yamashita M et al. Hair dyes. Jpn J Acute Med 1988:12:1509-1512.

[8]. Ishizawa J, Takahashi N. Hair dyes. Jpn J Acute Med 1996:20:1584-1585.

[9]. Shima H. A study on hair dye poisoning. Med J Nihon Univ
1966:19:2633-2638.

[10]. Nakao M, Takeda Y. Distribution, excretion and metabolism of p-phenylenediamine in rat, Yakugaku Zasshi 1979:99:1149-1153.

[11]. Goetz N, Laserre P, Bore P, Kalopissis G. Percutaneos absorption of pphenylenediamine during an actual hair dyeing procedure, Int. J. Cosmet. Sci. 1988:10:63-73.

[12]. Kawakubo Y, Merk HF, Al Masaoudi T, Sieben S, and Blomeke B. NAcetylation of paraphenylenediamine in human skin and keratinocytes. $J$ Pharmacol Exp Ther 2000:292:150-155.

[13]. Koyama K, Ogasawara N, Kadomatsu K et al. A study on a blood concentration determination system for patients in acute drug poisoning. IRYO 2000:54:565-570.

[14]. Stambouli A, Bellimam MA, El Karni N, Bouayoun T, El Bouri A. Optimization of an analytical method for detecting paraphenylenediamine (PPD) by GC/MS-ion trap in biological liquids. Forensic Science International 2004:146S: S87-S92.

[15]. Wang L and Tsai S. Simultaneous determination of oxidative hair dye p-phenylenediamine and its metabolites in human and rabbit biological fluids. Analytical Biochemistry 2003:312: 201-207.

[16]. Meyer A, Blömekeb B, Fischer K. Determination of p-phenylenediamine and its metabolites MAPPD and DAPPD in biological samples using HPLC-DAD and amperometric detection. Journal of Chromatography $B$, 2009:877:1627-1633

[17]. Hooff GP, van Huizen NA, Meesters RJW, Zijlstra EE, Abdelraheem M, et al. Analytical Investigations of Toxic p-Phenylenediamine (PPD) Levels in Clinical Urine Samples with Special Focus on MALDI-MS/MS. PLoS ONE 2011:6:e22191. doi:10.1371/journal.pone.0022191.

[18]. CORBETT, JF. Autoxidation of p-phenylenediamine. J. Sot. Cosmet. Chem. 1972:23:683-93.

[19]. Jahn S., Faber H., Zazzeroni R., Karst U. Electrochemistry/mass spectrometry as a tool in the investigation of the potent skin sensitizer p phenylenediamine and its reactivity toward nucleophiles. Rapid Commu. Mass Spectrom. 2012:26:1453-1464. 